\title{
Determination of meteor-head echo trajectories using the interferometric capabilities of MAARSY
}

\author{
C. Schult, G. Stober, J. L. Chau, and R. Latteck \\ Leibniz Institute of Atmospheric Physics at the Rostock University, Schloss-Str. 6, 18225 Kühlungsborn, Germany \\ Correspondence to: C. Schult (schult@iap-kborn.de)
}

Received: 30 May 2013 - Revised: 8 August 2013 - Accepted: 23 September 2013 - Published: 29 October 2013

\begin{abstract}
During the flight of a meteoroid through the neutral atmosphere, the high kinetic energy is sufficient to ionize the meteoric constituents. Radar echoes coming from plasma irregularities surrounding the meteoroids are called meteor-head echoes, and can be detected by HPLA radar systems. Measurements of these echoes were conducted with MAARSY (Middle Atmosphere Alomar Radar System) in December 2010. The interferometric capabilities of the radar system permit the determination of the meteor trajectories within the radar beam with high accuracy. The received data are used to gain information about entry velocities, source radiants, observation heights and other meteoroid parameters. Our preliminary results indicate that the majority of meteors have masses between $10^{-10}$ and $10^{-3} \mathrm{~kg}$ and the mean masses of the sporadic meteors and Gemenids meteors are $\sim 10^{-8} \mathrm{~kg}$.
\end{abstract}

Keywords. Atmospheric Composition and Structure (Middle Atmosphere - Composition and Chemistry) - Interplanetary Physics (Interplanetary Dust) - Ionosphere (Ion Chemistry and Composition)

\section{Introduction}

When meteoroids enter the earth's atmosphere, they typically ablate at the altitude range between $70-140 \mathrm{~km}$ and have geocentric velocities of $11-72 \mathrm{~km} \mathrm{~s}^{-1}$. The deposited meteoric material influences the atmospheric physics at the height of the mesosphere-lower thermosphere (MLT). Through recondensation processes of the ablated material, meteoric smoke particles (Megner et al., 2006) and metal layers evolve (e.g. Höffner and Friedmann, 2004; Rapp and Strelnikova, 2009) in the altitude range of $80-105 \mathrm{~km}$. Furthermore, these particles are considered to be relevant for the formation of noc- tilucent clouds and polar mesospheric summer echoes (Rapp and Thomas, 2006), which are useful tracers for the dynamical properties and climate trends in the mesosphere (Rapp and Lübken, 2004). For a better understanding of these phenomena, it is essential to quantify the meteoric mass input. This quantification varies strongly with different measurement methods (5-270 ton per day) (e.g. Ceplecha et al., 1998; Love and Brownlee, 1993; Nesvorny et al., 2010; Mathews et al., 2001) and is therefore not well understood.

In recent years the detection of meteor-head echoes with high power and larger aperture (HPLA) radars gained more and more acceptance (e.g. Sato et al., 2000; Close and Hunt, 2000; Chau and Woodman, 2004; Pellinen-Wannberg et al., 2004; Chau and Galindo, 2008; Sparks et al., 2010; Kero et al., 2011). This technique uses the fact that the ablation process forms a detectable plasma around the meteoroid. The backscattered signal is called the meteor-head echo. The use of multiple receiver systems offers the possibility to gain much more information from a single meteor event. Stober et al. (2013) shows an overview of meteor-head echo measurements with the new radar system MAARSY in comparison with measurements of a standard meteor radar during the ECOMA campaign on the Geminids in 2010. In this paper we present a more detailed description of the used meteorhead echo experiment and the data analysis process. The detection threshold parameters are slightly different and in addition a calculation of the dynamic mass is involved.

\section{MAARSY}

The Middle Atmosphere Alomar Radar System (MAARSY) was installed in 2010 on the Norwegian island Andøya $\left(69.30^{\circ} \mathrm{N}, 16.04^{\circ} \mathrm{E}\right) . \mathrm{MAARS} Y$ is a monostatic HPLA radar, consisting of 433 Yagi antennas. The aperture is nearly 
Table 1. Meteor-head echo experimental set-up during the ECOMA campaign in December 2010 (Latteck et al., 2012b); Pulse Repetition Frequency (PRF), Inter-Pulse Period (IPP).

\begin{tabular}{ll}
\hline Parameter & Meteor-head exp. \\
\hline PRF & $700 \mathrm{~Hz}$ \\
Wave form & mono \\
Pulse length & $48 \mu \mathrm{s}$ \\
IPP & $1.43 \mathrm{~ms}$ \\
Duty cycle & $3.36 \%$ \\
Sampling start range & $72.9 \mathrm{~km}$ \\
Sampling end range & $148.5 \mathrm{~km}$ \\
Sampling resolution & $900 \mathrm{~m}$ \\
Sampling rate & $6 \mu \mathrm{s}$ \\
Range gates & 85 \\
Number of data points & 8192 \\
Time resolution & $1.43 \mathrm{~ms}$ \\
\hline
\end{tabular}

circular with a diameter of $90 \mathrm{~m}$. The fact that every antenna has its own transceiver module makes it very flexible in phase control and power output. The operational frequency of MAARSY is $53.5 \mathrm{MHz}$; most of the important technical details and first results are shown in (Latteck et al., 2010, $2012 b, a)$. The experimental set-up for the measurement during the ECOMA campaign in 2010 is listed in Table 1.

The receiver separation for the interferometric analysis is shown in Fig. 1. Receiver Rx1 contains the combined signals of all antenna subgroups $\mathrm{Rx} 2-\mathrm{Rx} 8$ and has therefore the best signal-to-noise ratio. One colour coded subgroup in Fig. 1 contains 49 antennas and is hereafter called "anemone". The distance $(d)$ between the outer anemones $\mathrm{R} \times 2-\mathrm{R} \times 7$ and the inner anemone $\mathrm{Rx} 8$ is $28 \mathrm{~m}$.

\section{Interferometric Analysis}

The first step in the meteor-head echo analysis requires the search for potential meteor-head echo events. Therefore the signal-to-noise ratio (SNR) of a full measurement section of 8192 IPPs (11.7 s) of receiver Rx1 is calculated. Although all sampling points of an event with a $S N R \geq 7 \mathrm{~dB}$ were used for further calculations, only events with a threshold of $\mathrm{SNR}_{\text {tres }} \geq 10 \mathrm{~dB}$ where selected. The second filtering mechanism includes a range-time fit of the detected events, which provides the radial velocity $v_{\text {rad. }}$. This parameter allows us to distinguish between meteor-head echoes and likely meteor trails. While meteor trails stay on a constant range level, most meteor-head echoes approach the radar over time. As a consequence, events slower than $-5 \mathrm{~km} \mathrm{~s}^{-1}$ were rejected. One example for a typical meteor-head echo is shown in Fig. 2.

The next step is the interferometric analysis of the meteorhead echo. A cross correlation between the signals of different receivers provides the phase differences and therefore information about the position of the echo within the radar beam. The calculation of the target position involves a plane

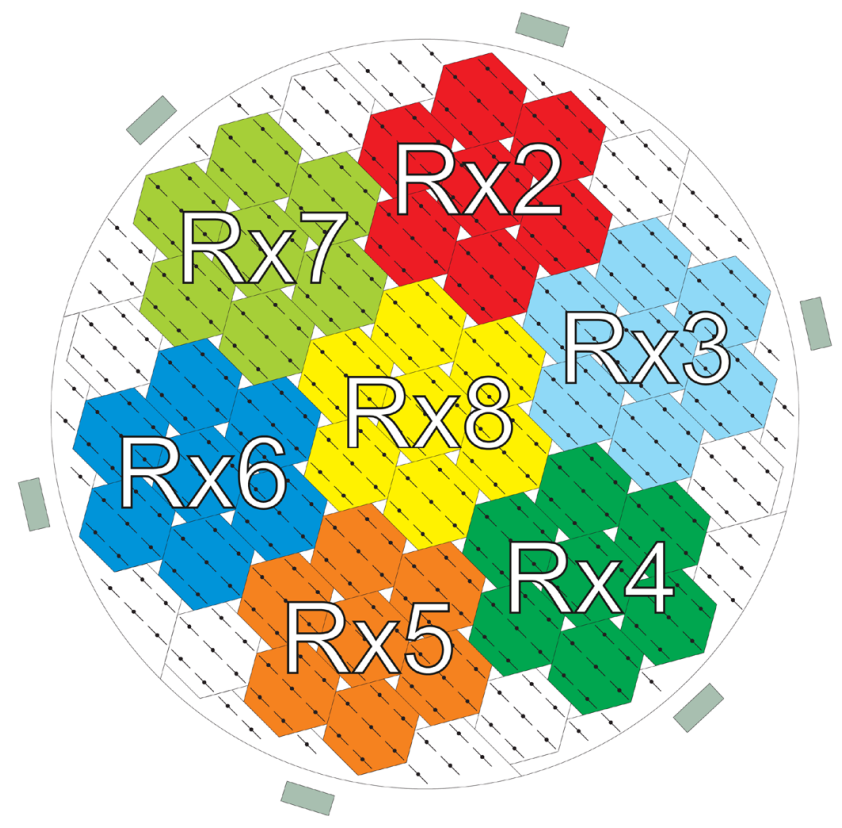

Fig. 1. MAARSY receiver constellation during the ECOMA campaign.

wave approximation and is done in accordance with Valentic et al. (1997) and Lau et al. (2006). For $n$ receiver constellations the following matrix equation is obtained:

$$
\underbrace{\left(\begin{array}{c}
\Phi_{1} \\
\vdots \\
\Phi_{n}
\end{array}\right)}_{\boldsymbol{\Phi}}=\underbrace{-\frac{2 \pi}{\lambda}\left(\begin{array}{cc}
d_{1} \cos \left(\gamma_{1}\right) & d_{1} \sin \left(\gamma_{1}\right) \\
\vdots & \vdots \\
d_{n} \cos \left(\gamma_{n}\right) & d_{n} \sin \left(\gamma_{n}\right)
\end{array}\right)}_{\mathbf{M}} \cdot \underbrace{\left(\begin{array}{c}
\cos (\alpha) \cos (\beta) \\
\cos (\alpha) \sin (\beta)
\end{array}\right)}_{\boldsymbol{w}},
$$

with the phase difference vector $(\boldsymbol{\Phi})$, the radar geometry matrix $(\mathbf{M})$ and the angle vector $(\boldsymbol{w})$, which contains the azimuth and elevation angle $(\beta, \alpha)$. M consists of the radar wavelength $(\lambda)$ and the distances $(d)$ and polar angles $(\gamma)$ between the correlated receivers. In this analysis all receiver combinations with the inner anemone $\operatorname{Rx} 8$ are used $(\boldsymbol{\Phi}=$ $\left.\left[\Phi_{8-2} \ldots \Phi_{8-7}\right]\right)$.

$\boldsymbol{\Phi}=\mathbf{M} \cdot \boldsymbol{w}$.

Rewriting Eq. (2) by using a least square solution of the overdetermined system obtains the angle vector $\boldsymbol{w}$.

$\boldsymbol{w}=\left(\begin{array}{l}w_{1} \\ w_{2}\end{array}\right)=\left(\mathbf{M}^{T} \mathbf{M}\right)^{-1} \mathbf{M}^{T} \boldsymbol{\Phi}$.

The detection angles $(\beta, \alpha)$ are given by

$$
\begin{aligned}
& \beta=\tan ^{-1}\left(\frac{w_{2}}{w_{1}}\right), \\
& \alpha=\cos ^{-1}\left(\frac{w_{1}}{\cos \beta}\right) .
\end{aligned}
$$




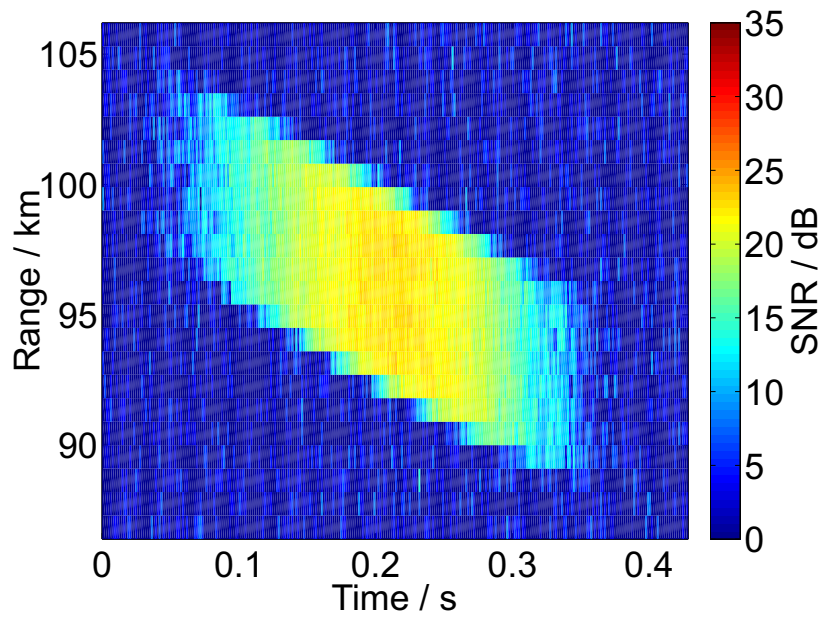

Fig. 2. Example of a typical meteor-head echo, Figs. 2-6 are related to the same echo.

An averaging over all range gates and four successive pulses was performed to improve the accuracy of the position, especially for weak signals. Figure 3 shows the phase differences of the meteor event in Fig. 2 between the inner receiver $\mathrm{Rx} 8$ and the two exterior receivers $\mathrm{Rx} 2$ and $\mathrm{Rx} 4$. Figure 4 visualizes the trajectory with a colour coded altitude of the event. The red circles indicate minima of the radiation pattern, while the green hexagon shows the ambiguity area due to phase jumps. The hexagon structure is a result of the geometrical arrangement of the receiver anemones. There are always two interferometric baselines with different signs (e.g. Rx8-Rx4 and Rx8-Rx7), which generate the same two opposing ambiguity lines of the hexagon. To avoid jumps in the meteor trajectory near the ambiguity lines, a phase unwrapping was performed.

Every space coordinate $x, y$ and $z$ is fitted separately over time and reveals the velocity components $v_{x}, v_{y}$ and $v_{z}$. The azimuth $(\varphi)$, elevation $(\vartheta)$ and vector velocity $(v)$ of the meteor-head is given by

$\varphi=\frac{\pi}{2}-\arctan \left(\frac{v_{y}}{v_{x}}\right)$,

$\vartheta=\arctan \left(\sin (\varphi) \frac{v_{z}}{v_{x}}\right)$

$v=\sqrt{v_{x}^{2}+v_{y}^{2}+v_{z}^{2}}$.

The standard error for the fitted trajectories depends on the SNR, number of independent samples and the geometry of the flight, therefore the accuracy of the meteor-head trajectories differ. For over $79 \%$ of the trajectories presented here, the azimuth angle ( $83 \%$ in elevation) has a standard

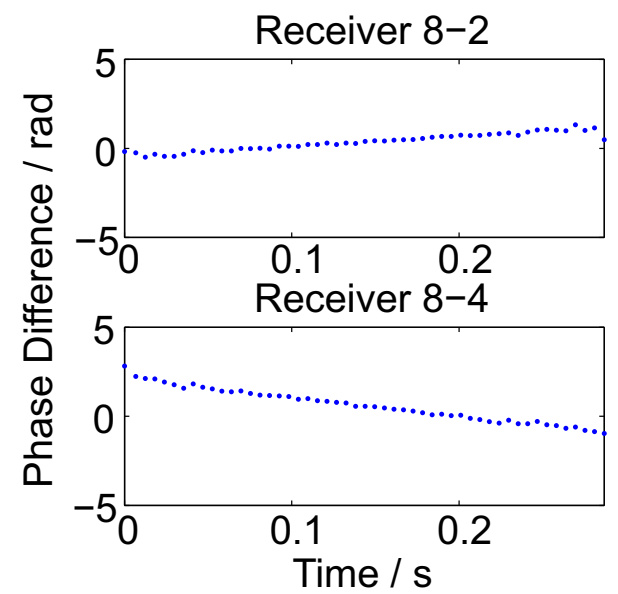

Fig. 3. Measured phase differences between receiver $\mathrm{Rx} 8$ and the exterior receiver $\mathrm{Rx} 2$ and $\mathrm{Rx} 4$.

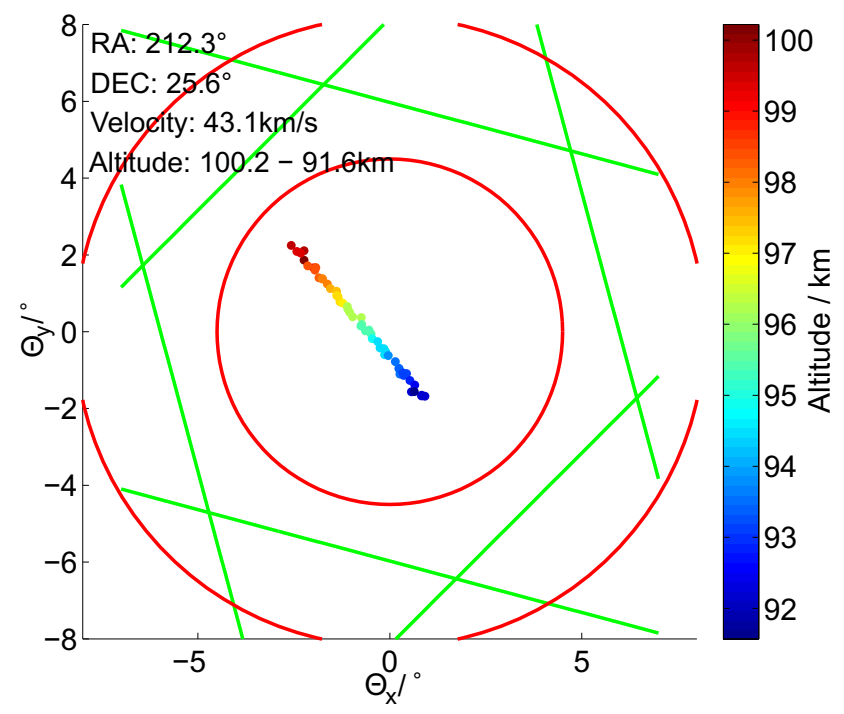

Fig. 4. Trajectory of the meteor in zenith distance angle $(\Theta)$ with colour coded altitude, right ascension (RA), declination (DEC) velocity and begin/end altitude parameters are located in the left corner.

error of less than $3^{\circ}$. The velocity standard error is for over $87 \%$ of the detected meteors less than $3 \mathrm{~km} \mathrm{~s}^{-1}$. Events with standard errors greater than $5^{\circ}$ in direction or $5 \mathrm{~km} \mathrm{~s}^{-1}$ in velocity were neglected.

The deceleration of the meteor-head echo is calculated performing a pulse-to-pulse phase correlation (e.g. Chau and Woodman, 2004; Kero et al., 2012) of the signal of receiver $\mathrm{Rx} 1$, which provides the radial velocity $v_{\mathrm{r}}$

$v_{\mathrm{r}}=-\frac{\mathrm{d} \Phi}{\mathrm{d} t} \frac{\lambda}{4 \pi}$,

where $d \Phi$ is the phase difference of the pulses and the time step $\mathrm{d} t(\mathrm{~d} t=\mathrm{IPP})$. With the knowledge of the meteor trajectory the apparent deceleration can be corrected for the 


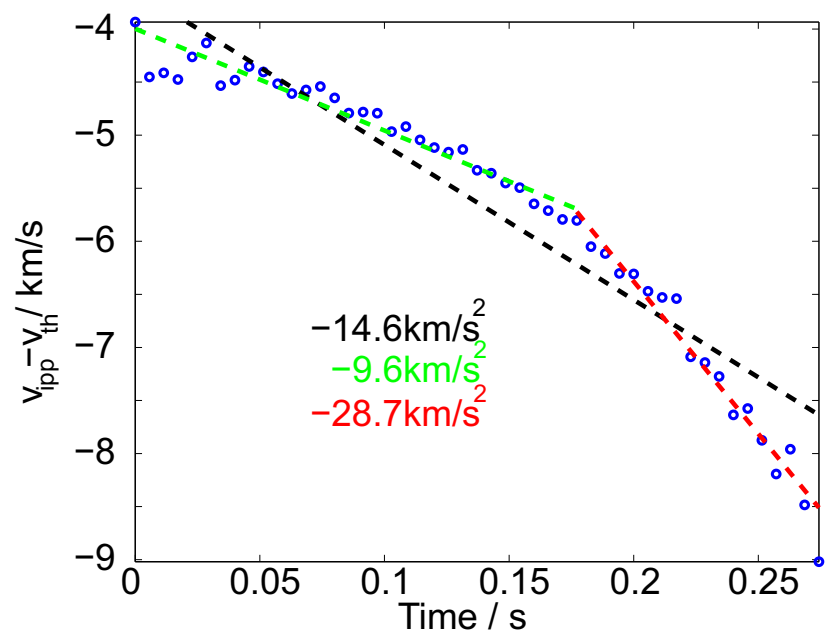

Fig. 5. Deceleration of the meteor-head echo; $v_{\text {IPP }}$ is the velocity calculated due to phase differences of different pulses; subtracted is the theoretical velocity change $\left(v_{\text {th }}\right)$ due to the geometrical contribution (geometrical acceleration: $-11.96 \mathrm{~km} \mathrm{~s}^{-2}$ ); green line: fit at the beginning of the event $(0-0.18 \mathrm{~s})$; red line: fit at the end of the event; black line: fit of the whole event.

geometrical contribution. At the end the absolute velocity shift of the meteor is reproduced. An averaging of four time steps is performed. Figure 5 shows the velocity shift for our chosen example. The curve exhibits a clear knee at $0.18 \mathrm{~s}$, where the deceleration enhances by $19 \mathrm{~km} \mathrm{~s}^{-2}$. This enhancement in the deceleration might be a result of a strong mass loss due to a fragmentation of the meteoroid or a change of the ablation regime. The occurrence of fragmentation or differential ablation during the heating process is also considered by other authors (e.g. Campbell-Brown and Koschny, 2004; Janches et al., 2009).

A further step in the analysis algorithm is the determination of the radar cross section (RCS) of the meteor-head by using the radar equation for hard targets (e.g. Baggaley, 2002; Kero et al., 2008b)

$\mathrm{RCS}=\frac{(4 \pi)^{3} r^{4} P_{\mathrm{R}}}{G^{2}\left(\Theta_{x}, \Theta_{y}\right) \lambda^{2} P_{\mathrm{T}}}$,

with $r$ the range of the meteor-head echo, $G$ the antenna gain at the meteor position (zenith distance angles in $x$ and $y$ direction $\left.\Theta_{x, y}\right), \lambda$ the radar wave length and $P_{\mathrm{T}}$ the transmitted power of the radar. The antenna gain is calculated with a numerical electromagnetic code (NEC) which revealed good experimental results in a passive scan mode (Renkwitz et al., 2012, 2013). $P_{\mathrm{R}}$ is the received power which is calculated from the SNR, the Boltzmann constant $k_{\mathrm{B}}$, the bandwidth $f_{\mathrm{B}}$ and the noise temperature $T_{\mathrm{n}}$

$P_{\mathrm{R}}=\mathrm{SNR} \cdot T_{\mathrm{n}} k_{\mathrm{B}} f_{\mathrm{b}}$.

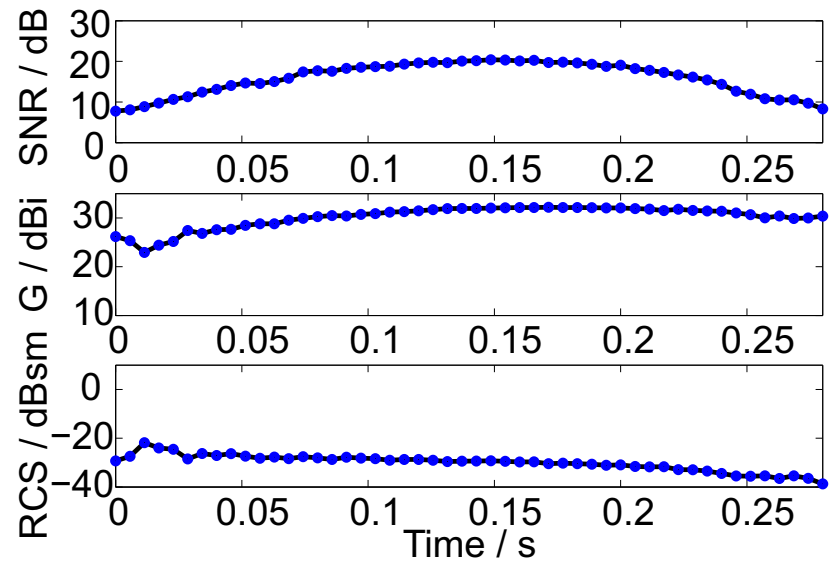

Fig. 6. Top: SNR; centre: antenna gain on the meteoroid position; bottom: RCS of the meteor-head echo.

The noise temperature is strongly radar and direction dependent. To get the absolute sky noise temperature at different times, a convolution of the MAARSY antenna gain pattern with a cosmic sky model is used (de Oliveira-Costa et al., 2008; Stober et al., 2011b; Renkwitz et al., 2012). Figure 6 shows the SNR, the antenna gain and the RCS of the meteorhead echo at different time steps. The meteor-head echo example shows a constant slight decrease of the RCS after a first small peak during the flight through the radar beam. It has to be mentioned that two effects negatively influence the RCS calculation. The first one is a consequence of the polarized antenna system and the occurrence of Faraday rotation (Chau et al., 2013). During the propagation through the ionized atmosphere, the transmitted polarized radio wave can be rotated out of the detection plane of the antenna system, which reduces the received SNR of the meteor-head echo (Elford and Taylor, 1997). The Faraday rotation especially influences the measurement of higher meteors. The second problem lies in the ambiguity limitations of the radar system. Strong meteor events in the first or second side lobes are intrinsically projected in the ambiguity area of the main beam. This space offset has a small influence on the trajectory parameters, but leads to an underestimation of the RCS and an incorrect calculation of the deceleration.

\section{Results}

To categorise the detected meteors, it is efficient to transform the horizontal coordinates $(\varphi, \vartheta)$ into elliptical heliocentric coordinates (Jones and Brown, 1993). In Fig. 7 a normalized meteor radiant density map is shown. The darkest red spot (208 ${ }^{\circ}$ Long., $12^{\circ}$ Lat. in Fig. 7) corresponds to the Geminid meteor shower, which was active during most of the experiment. Only about $5 \%$ of the detected meteors belong to the Geminid shower, but these meteors originate from a narrow spot on the sky. As is expected from HPLA meteor-head 


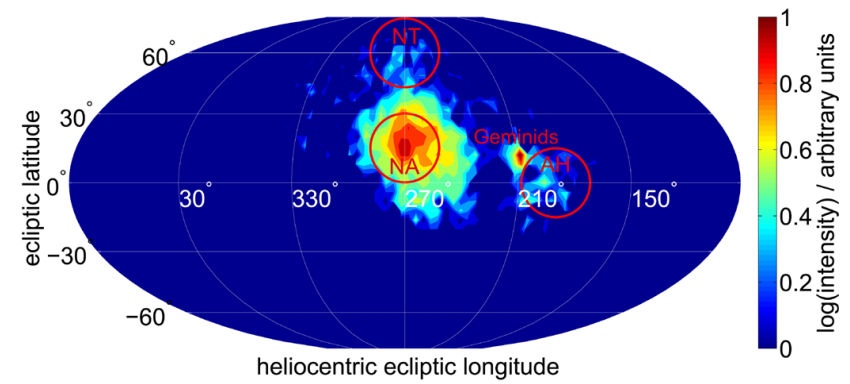

Fig. 7. Detected meteor-head echo radiant density in heliocentric coordinates, North Apex (NA), Antihelion (AH), North Toroidal (NT).

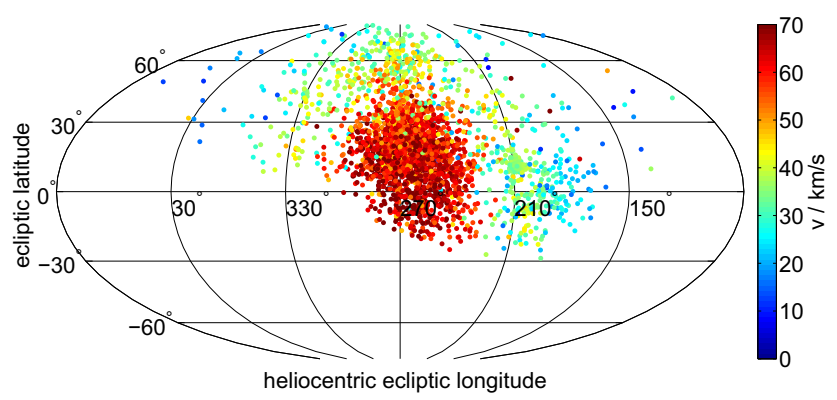

Fig. 8. Distribution of detected meteors in heliocentric coordinates with colour coded velocity.

echo observations (e.g. Janches et al., 2003; Chau et al., 2007; Kero et al., 2008a; Pifko et al., 2013), most of the meteors are related to the fastest group of sporadic meteors. The North Apex source is widely spread in the centre of the map. The Antihelion and Northern Toroidal sporadic sources $\left(200^{\circ}\right.$ Long., $0^{\circ}$ Lat. and $270^{\circ}$ Long., $60^{\circ}$ Lat. in Fig. 7 ) are represented very weakly in the measurements.

In Figs. 8 and 9 the velocity distribution is shown. It spreads over the whole spectrum of possible meteoroid velocities. In the map of Fig. 8 the fast meteors are located in the apex direction, which corresponds to the peak at $60 \mathrm{~km} \mathrm{~s}^{-1}$ in the velocity histogram of Fig. 9. The second peak at $35 \mathrm{~km} \mathrm{~s}^{-1}$ is a result of the two other sporadic sources, which in contrast to the meteor-head echo measurements of several HPLA radars that also see the peak in the low velocity regime: Jicamarca (Chau and Woodman, 2004), MU radar (Kero et al., 2011), ALTAIR (Close et al., 2007) the part of slower meteors in this measurement is proportionally higher. Probably the deviations can be explained by the different radar locations and measurement times in connection with the atmospheric filtering and earth blocking. For the detection of meteors with HPLA radar systems these effects have been simulated by Janches et al. (2006); Fentzke and Janches (2008). Chau et al. (2007) chose a time-integrated angular sensitivity function to normalize the different sporadic meteor sources in the measurements. The angular sensitivity function simply depends on the elevation angle of the

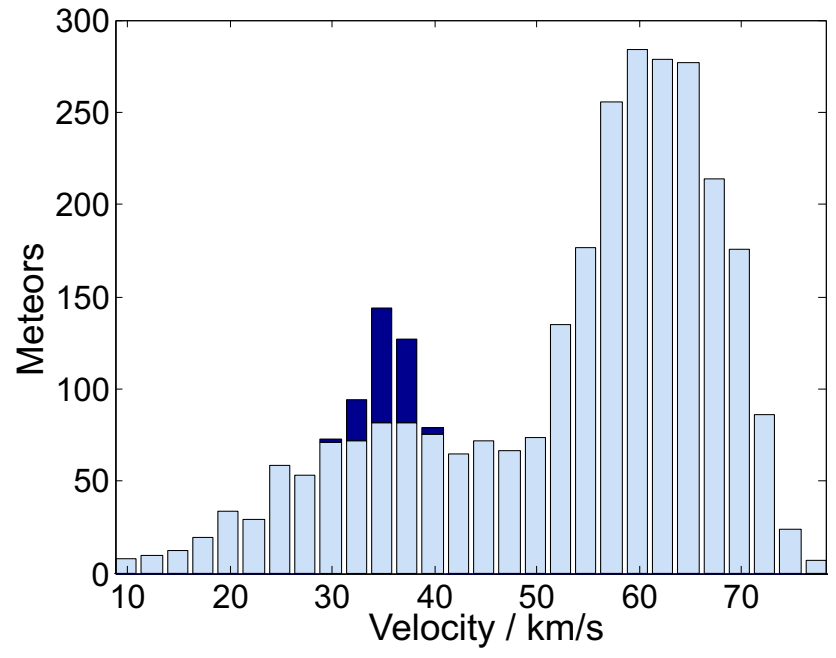

Fig. 9. Histogram of the velocity distribution; dark blue bars corresponds to Geminid meteors; light blue bars for sporadics.

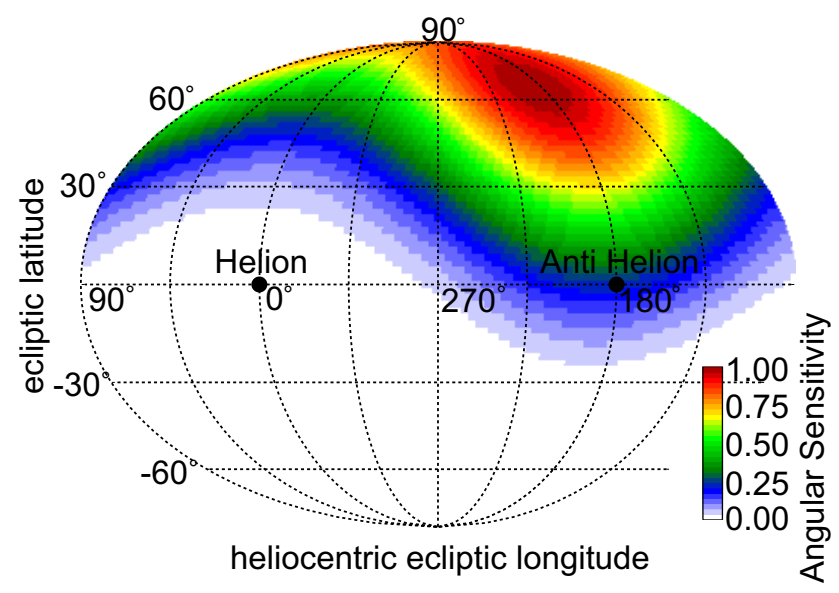

Fig. 10. MAARSY's time integrated angular sensitivity for the observation time during the ECOMA Geminid campaign in accordance with Chau et al. (2007).

meteor-head and offered good results in the comparison of symmetrical sources (i.e. Helion and Anti Helion). The angular sensitivity function for MAARSY during the ECOMA campaign is plotted in Fig. 10 and is in a good agreement with the map in Fig. 7. Only the three observed sporadic sources (North Toroidal, Anti Helion, North Apex) lie within the detectable regime during the campaign. The fact that the South Apex is located outside of the detectable area and the North Apex lies in a more or less insensitive regime, explains the differences in the velocity distributions in comparison with other radar systems. In agreement with previous meteorhead observations (e.g. Chau et al., 2007; Close et al., 2007; Kero et al., 2011; Pifko et al., 2013), the Apex source is the dominant sporadic source.

The altitude distribution of the detected meteor-head echoes in Fig. 11 is spread from 80 to $130 \mathrm{~km}$ and has its 


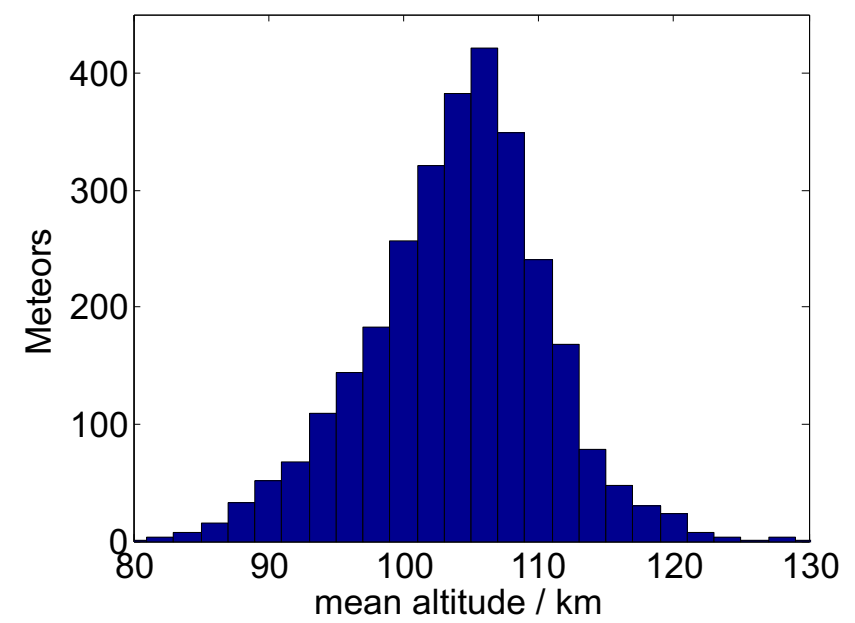

Fig. 11. Histogram of the mean meteor-head echo altitudes.

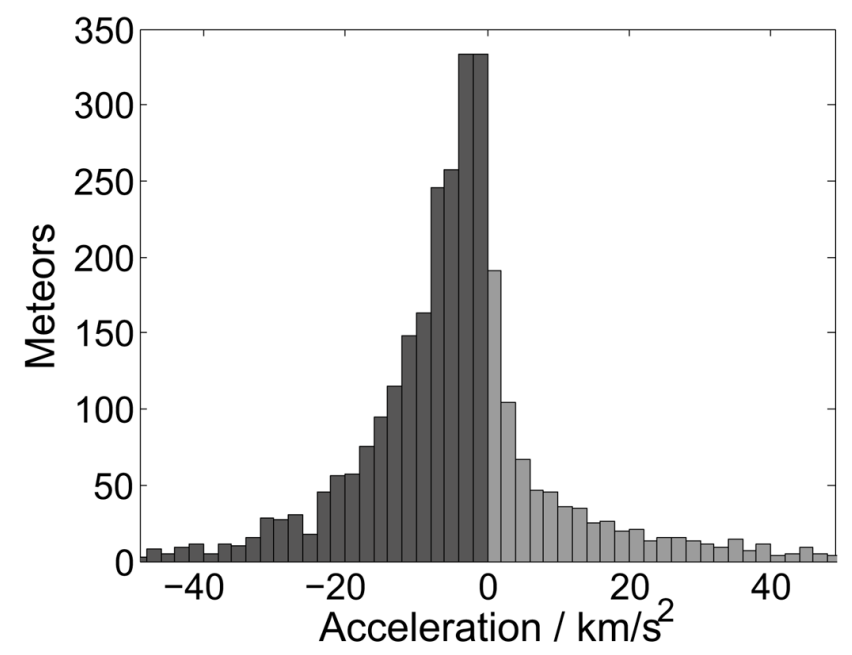

Fig. 12. Histogram of the observed meteor accelerations; the light grey part (positive accelerations) is ignored for further calculations.

maximum around $106 \mathrm{~km}$, which is mainly controlled due to the measurement frequency and the neutral air density (e.g. Westman et al., 2004; Stober et al., 2012). Another aspect is the sensitivity to the sporadic sources in connection with the source velocity distributions. Faster meteors appear at higher altitudes, which influences the altitude statistics (Chau et al., 2007). This effect is also shown in the altitude vs. deceleration plot in Fig. 14, where the black marks indicate meteors with geocentric velocities greater than $50 \mathrm{~km} \mathrm{~s}^{-1}$. Note that these meteors occur at higher altitudes and mainly belong to the Apex source.

Figure 12 shows the calculated mean accelerations of the detected meteors. The light grey part of the histogram indicates the part of positive accelerations $(\sim 25 \%)$. This part is neglected in the further calculations/figures and has its cause in likely ambiguous side lobe detections or to noisy phase shifts and subsequent unwrapping problems. Chau

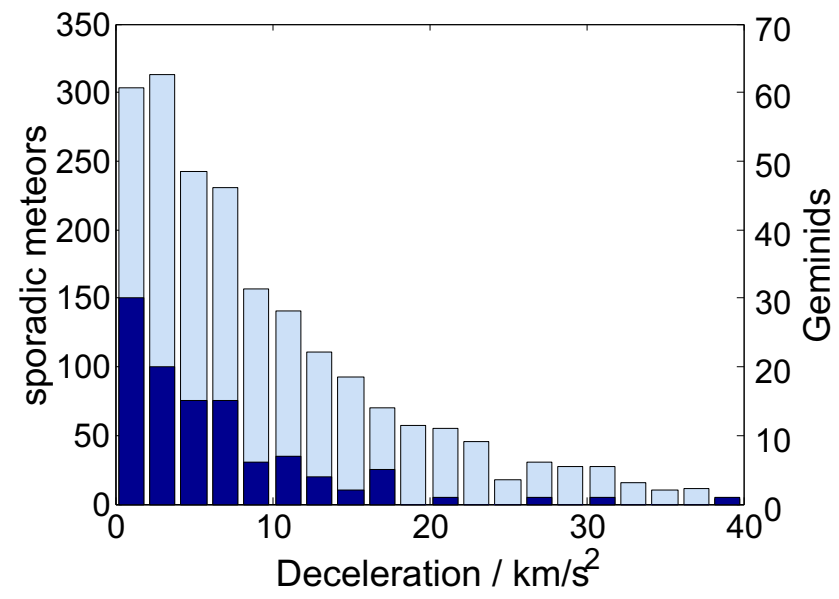

Fig. 13. Histogram of the meteor decelerations; dark blue: Geminids; light blue: sporadic meteors.

et al. (2009) found a side lobe detection rate of $15 \%$ for the HPLA radar PFISR; this demonstrates that the effect should not be neglected. At the moment for MAARSY no comparable estimation exists, although we expect a lower side lobe detection rate. The remaining deceleration distribution is plotted in Fig. 13 and separated in Geminid shower meteors (dark blue) and sporadic meteors (light blue). Due to the large part of fast meteors (Apex source), the sporadic meteor distribution includes proportionally more meteors with stronger decelerations. While the light blue histogram contains meteoroids with different velocities and compositions, the distribution of the Geminid shower histogram is mainly a result of different meteor masses.

The altitude vs. deceleration plot in Fig. 14 shows no clear statistical dependance between the two parameters for sporadic meteors, whereas the Geminid meteors show a slight increase in deceleration with decreasing altitude. While the Geminid meteors probably have nearly the same physical properties (e.g. velocity, density and chemical constituents), the properties of sporadic meteors varies substantial between and within the different sporadic sources. Therefore the plot in Fig. 14 underlines the differences between sporadic and shower meteors.

To get an estimation of the detected meteor masses, the mean decelerations $\frac{\mathrm{d} v}{\mathrm{~d} t}$ and velocities $v$ are further used for the calculation of the dynamical meteor masses (e.g. McKinley, 1961; Sparks et al., 2009; Stober et al., 2011a)

$\frac{\mathrm{d} v}{\mathrm{~d} t}=\frac{c_{w} A}{m^{\frac{1}{3}} \rho^{\frac{2}{3}}} \rho_{\text {air }} v^{2}$.

$A$ is the dimensionless shape factor and is set to 1.21 assuming a spherical body (McKinley, 1961). The detection altitudes and small particle sizes lead to the assumption of a free flow regime, which is discussed in detail in Campbell-Brown and Koschny (2004). As a consequence of the free flow regime, the drag coefficient $\left(c_{w}\right)$ of the detected meteoroids 


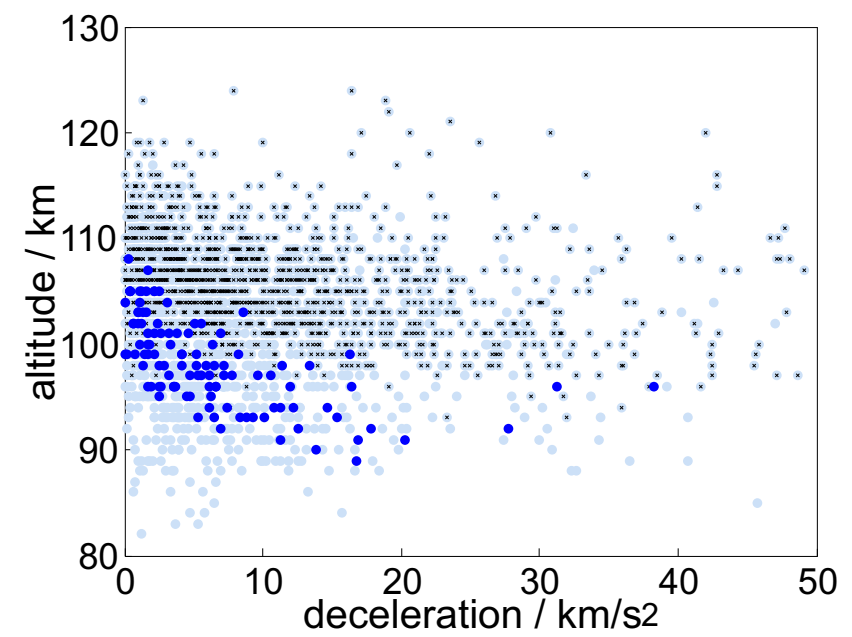

Fig. 14. Deceleration vs. Altitude; dark blue: Geminids; light blue: sporadic meteors; black marked sporadic meteors indicate velocities greater than $50 \mathrm{~km} \mathrm{~s}^{-1}$.

is set to 1 . The air density $\left(\rho_{\text {air }}\right)$ at the mean ablation altitudes are taken from the NRLMSISE-00 model (Picone et al., 2002). The particle density $(\rho)$ is set to $2350 \mathrm{~kg} \mathrm{~m}^{-3}$ for Geminid meteors as a result of the spectral analysis of the parent body asteroid (3200) Phaethon (Licandro et al., 2007; Stober et al., 2011a). Most of the detected sporadic meteors have strong elliptical orbits and therefore very likely a cometary origin with lower densities. Hence the density for sporadic meteors is set to a lower value: $\rho=1000 \mathrm{~kg} \mathrm{~m}^{-3}$.

The resulting histogram of the dynamical masses is plotted in Fig. 15. For the chosen density values the mass histograms of the sporadic and Geminid meteors have the same shape and are centred around $10^{-8} \mathrm{~kg}$. This might be an indicator for a well-chosen density ratio between the two meteor populations. Furthermore, the radar systems seem to be sensitive in the mass region from $10^{-3}$ to $10^{-10} \mathrm{~kg}$ and only a small fraction of the detected events have lower masses. These low masses (smaller than $10^{-10} \mathrm{~kg}$ ) might not be quite realistic and are probably a consequence of the assumptions made in the dynamical mass equation. In the ablation model calculations of Vondrak et al. (2008) and Pifko et al. (2013) such low mass meteoroids would not start to ablate or were to small to be detected.

Figure 16 shows the histogram of the calculated mean RCS of the meteors. The values lie between -10 and $-40 \mathrm{dBsm}$ (decibel per square meter) with a maximum at $-34 \mathrm{dBsm}$. The weakest meteors of $-40 \mathrm{dBsm}$ can only be detected in the middle of the beam, where the highest radar gain is obtained. The decrease of the count rate to higher values is the result of the low probability of these big events. For the future a more detailed analysis of the RCS in comparison with other meteor parameters is planned. Therefore it is important to reduce the error of side lobe detections by adding smaller receiver baselines.

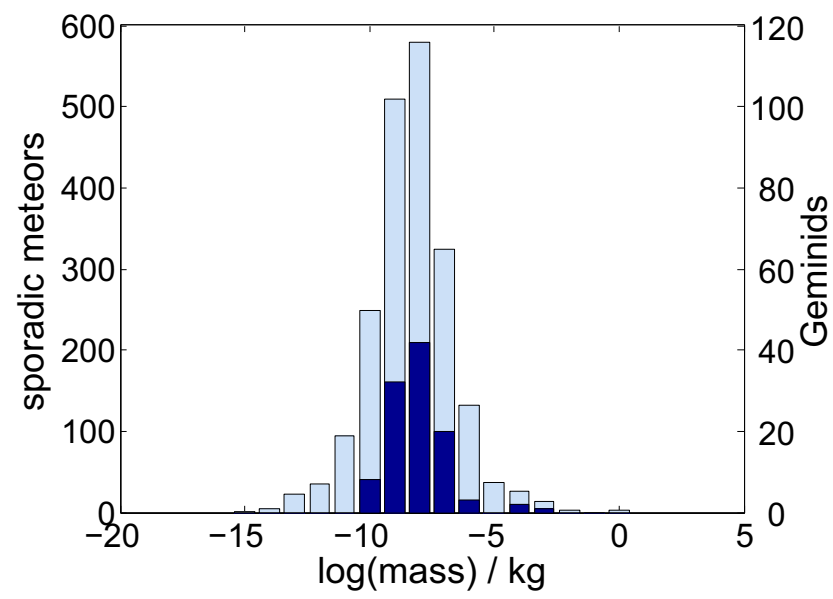

Fig. 15. Histogram of the calculated dynamic meteor masses; dark blue: Geminids; light blue: sporadic meteors.

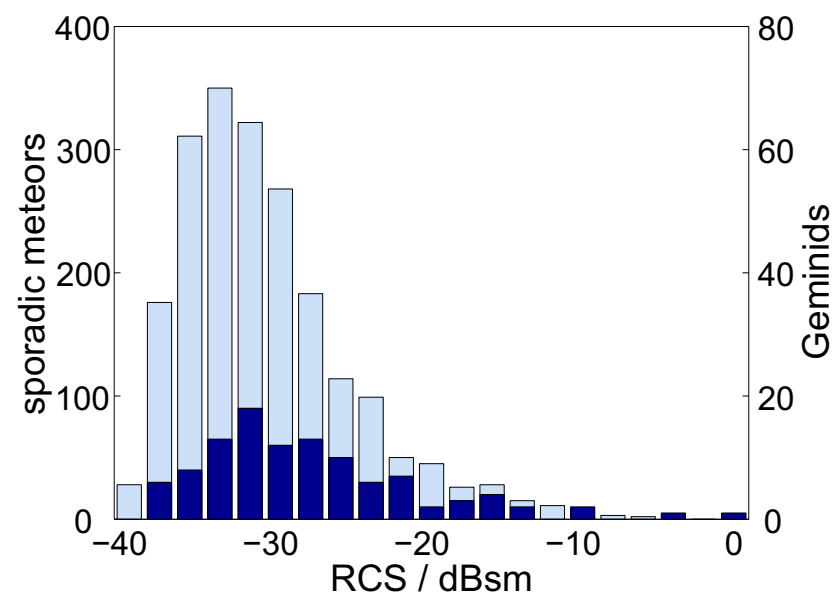

Fig. 16. Histogram of mean RCS; dark blue: Geminids; light blue: sporadic meteors.

\section{Conclusions}

In December 2010 meteor-head echo measurements were conducted with the new MST radar system MAARSY. The analysis of the radar echoes of over 2900 meteor-heads show good results in the determination of the trajectories. The resulting heliocentric ecliptic maps are in agreement with other meteor measurements (e.g. Jones and Brown, 1993; Chau et al., 2007; Kero et al., 2011). Three sporadic sources (North Apex, Antihelion, North Toroidal) and the Geminid meteor shower could be identified, while the North Apex is the dominant meteor source in the data set. A known problem in the measurements presented are the appearance of ambiguous side lobe detections. A meteor with a large RCS can be passed through the side lobe, but incorrectly be projected into the main beam. This has negligible effects on the trajectory parameters (e.g. entry angle and velocity), but strongly influences the RCS and deceleration calculations. In the future the 
use of further receiver constellations is planned. By adding more baselines with different lengths, the ambiguity area can be extended, which helps us to reduce the ambiguity problem. To avoid the effects of Faraday rotation, MAARSY will be upgraded to a circular polarized antenna system. Also planned is the implementation of a Doppler-shifted pulsecoding algorithm to improve the SNR threshold and the range resolution (e.g. Chau and Woodman, 2004; Kero et al., 2012).

After cutting out obvious side lobe detections and events with unphysical acceleration curves (meteors with positive accelerations), the calculation of the dynamical meteor masses show the detection of meteoroids in the range of $10^{-10}$ to $10^{-3} \mathrm{~kg}$. Using a less conservative process could enable the possibility to detect even more events in that regime of the dynamical meteor masses. The detection of larger masses should also be possible but needs larger observation times due to the smaller probability of those meteor events and the small beam width of the radar system in comparison with all-sky specular meteor systems. The mass statistics for sporadic and shower meteors have the same shape, which is centred around $10^{-8} \mathrm{~kg}$, by using different particle densities for both meteor populations.

Acknowledgements. The technical support by the Andøya Rocket Range (ARR) is acknowledged. Furthermore we thank the technicians and engineers of the IAP in Kühlungsborn for the technical support and maintenance of the radar.

Topical Editor C. Jacobi thanks J. Fentzke and one anonymous referee for their help in evaluating this paper.

\section{References}

Baggaley, W. J.: Meteors in the Earth's Atmosphere, chap. Radar Observations, 123-147, Cambridge University Press, 2002.

Campbell-Brown, M. D. and Koschny, D.: Model of the ablation of faint meteors, A \& A, 418, 751-758, 2004.

Ceplecha, Z., Borovicka, J., Elford, W. G., Revelle, D. O., Hawkes, R. L., Porubcan, V., and Simek, M.: Meteor phenomena and bodies, Space Sci. Rev., 84, 327-471, 1998.

Chau, J. L. and Galindo, F.: First definitive observations of meteor shower particles using a high-power large-aperture radar, Icarus, 194, 23-29, 2008.

Chau, J. L. and Woodman, R. F.: Observations of meteor-head echoes using the Jicamarca $50 \mathrm{MHz}$ radar in interferometer mode, Atmos. Chem. Phys., 4, 511-521, doi:10.5194/acp-4-5112004, 2004.

Chau, J. L., Woodman, R. F., and Galindo, F.: Sporadic meteor sources as observed by the Jicamarca high-power large-aperture VHF radar, Icarus, 188, 162-174, 2007.

Chau, J. L., Galindo, R. F., Heinselman, J. C., and Nicolls, M. J.: Meteor-head echo observations using an antenna compression approach with the $450 \mathrm{MHz}$ Poker Flat Incoherent Scatter Radar, J. Atmos. Sol.-Terr., 71, 636-643, 2009.
Chau, J. L., Röttger, J., and Rapp, M.: PMSE strength during enhanced D region electron densities: Faraday rotation and Absorption effects at VHF frequencies, J. Atmos. Solar-Terrest. Phys., doi:10.1016/j.jastp.2013.06.015, in press, 2013.

Close, S. and Hunt, S. M.: Analysis of Perseid meteor head echo data collected using the Advanced Research Projects Agency Long-Range Tracking and Instrumentation Radar (ALTAIR), Radio Sci., 35, 1233-1240, 2000.

Close, S., Brown, P., Campbell-Brown, M., Oppenheim, M., and Colestocka, P.: Meteor head echo radar data: Mass-velocity selection effects, Icarus, 186, 547-556, 2007.

de Oliveira-Costa, A., Tegmark, M., Gaensler, B. M., Jonas, J., Landecker, T. L., and Reich, P.: A Model of Diffuse Galactic Radio Emission from $10 \mathrm{MHz}$ to $100 \mathrm{GHz}$, Mon. Not. R. Astron. Soc., 338, 247-260, doi:10.1111/j.1365-2966.2008.13376.x, 2008.

Elford, W. G. and Taylor, A. D.: Measurement of Faraday rotation of radar meteor echoes for the modelling of electron densities in the lower ionosphere, J. Atmos. Sol.-Terr. Phy., 59, 1021-1024, 1997.

Fentzke, J. T. and Janches, D.: A semi-empirical model of the contribution from sporadic meteoroid sources on the meteor input function in the MLT observed at Arecibo, J. Geophys. Res., 113, A03304, doi:10.1029/2007JA012531, 2008.

Höffner, J. and Friedman, J. S.: The mesospheric metal layer topside: a possible connection to meteoroids, Atmos. Chem. Phys., 4, 801-808, doi:10.5194/acp-4-801-2004, 2004.

Janches, D., Nolan, M. C., Meisel, D. D., Mathews, J. D., Zhou, Q. H., and Moser, D. E.: On the geocentric micrometeor velocity distribution, Journal of G, 108, 1222, doi:10.1029/2002JA009789, 2003.

Janches, D., Heinselman, C. J., Chau, J. L., Chandran, A., and Woodman, R.: Modeling the global micrometeor input function in the upper atmosphere observed by high power and large aperture radars, J. Geophys. Res., 111, A07317, doi:10.1029/2006JA011628, 2006.

Janches, D., Dyrud, L. P., Broadley, S. L., and Plane, J. M. C.: First observation of micrometeoroid differential ablation in the atmosphere, Geophys. Res. Lett., 36, L06101, doi:10.1029/2009GL037389, 2009.

Jones, J. and Brown, P.: Sporadic meteor radiant distributions: orbital survey results, Mon. Not. R. Astron. Soc., 265, 524-532, 1993.

Kero, J., Szasz, C., Pellinen-Wannberg, A., Wannberg, G., Westman, A., and Meisel, D. D.: Determination of meteoroid physical properties from tristatic radar observations, Ann. Geophys., 26, 2217-2228, doi:10.5194/angeo-26-2217-2008, 2008a.

Kero, J., Szasz, C., Wannberg, G., Pellinen-Wannberg, A., and Westman, A.: On the meteoric head echo radar cross section angular dependence, Geophys. Res. Lett., 35, L07101, doi:10.1029/2008GL033402, 2008b.

Kero, J., Szasz, C., Nakamura, T., Meisel, D. D., Ueda, M., Fujiwara, Y., Terasawa, T., Miyamoto, H., and Nishimura, K.: First results from the 2009-2010 MU radar head echo observation programme for sporadic and shower meteors: the Orionids 2009, Mon. Not. R. Astron. Soc., 416, 2550-2559, 2011.

Kero, J., Szasz, C., Nakamura, T., Terasawa, T., Miyamoto, H., and Nishimura, K.: A meteor head echo analysis algorithm for the lower VHF band, Ann. Geophys., 30, 639-659, doi:10.5194/angeo-30-639-2012, 2012. 
Latteck, R., Singer, W., Rapp, M., and Renkwitz, T.: MAARSY the new MST radar on Andoya/Norway, Adv. Radio Sci., 8, 1-6, 2010 , http://www.adv-radio-sci.net/8/1/2010/.

Latteck, R., Singer, W., Rapp, M., Renkwitz, T., and Stober, G.: Horizontally resolved structures of radar backscatter from polar mesospheric layers, Adv. Radio Sci., 10, 285-290, 2012a.

Latteck, R., Singer, W., Rapp, M., Vandepeer, B., Renkwitz, T., Zecha, M., and Stober, G.: MAARSY: The new MST radar on Andoya - System description and first results, Radio Sci., 47, RS1006, doi:10.1029/2011RS004775, 2012b.

Lau, E. M., Avery, S. K., Avery, J. P., Janches, D., Schafer, S. E. P. R., and Makarov, N. A.: Statistical characterization of the meteor trail distribution at the South Pole as seen by a VHF interferometric meteor radar, Radio Sci., 41, RS4007, doi:10.1029/2005RS003247, 2006.

Licandro, J., Campins, H., Mothe-Diniz, T., Pinilla-Alonso, N., and de Leon, J.: The nature of comet-asteroid transition object (3200) Phaethon, A \& A, 461, 751-757, 2007.

Love, S. G. and Brownlee, D. E.: A Direct Measurement of the Terrestrial Mass Accretion Rate of Cosmic Dust, Science, 262, 550553, 1993.

Mathews, J. D., Janches, D., Meisel, D. D., and Zhou, Q.-H.: The micrometeoroid mass flux into the upper atmosphere: Arecibo results and a comparison with prior estimates, Geophys. Res. Lett., 28, 1929-1932, 2001.

McKinley, D. W. R.: Meteor Science and Engineering, McGrawHill, 1961.

Megner, L., Rapp, M., and Gumbel, J.: Distribution of meteoric smoke - sensitivity to microphysical properties and atmospheric conditions, Atmos. Chem. Phys., 6, 4415-4426, doi:10.5194/acp-6-4415-2006, 2006.

Nesvorny, D., Jenniskens, P., Levison, H. F., Bottke, W. F., and Vokrouhlick, D.: Cometary Origin of the Zodiacal Cloud and Carbonaceous Micrometeorites. Implications for Hot Debris Disks, Astrophys. J., 836, 713-816, 2010.

Pellinen-Wannberg, A., Wannberg, E. M. G., and Westman, A.: The Hyperthermal Ionization and High Absolute Meteor Velocities Observed with HPLA Radars, Earth Moon Planets, 95, 627-632, 2004.

Picone, J. M., Hedin, A. E., and Drob, D. P.: NRLMSISE00 empirical model of the atmosphere: Statistical comparisons and scientific issues, J. Geophys. Res., 107, 1468, doi:10.1029/2002JA009430, 2002.

Pifko, S., Janches, D., Close, S., Sparks, J., Nakamura, T., and Nesvorny, D.: The Meteoroid Input Function and predictions of mid-latitude meteor observations by the MU radar, Icarus, 223, 444-459, 2013.

Rapp, M. and Lübken, F.-J.: Polar mesosphere summer echoes (PMSE): Review of observations and current understanding, Atmos. Chem. Phys., 4, 2601-2633, doi:10.5194/acp-4-2601-2004, 2004.
Rapp, M. and Strelnikova, I.: Measurements of meteor smoke particles during the ECOMA-2006 campaign: 1. Particle detection by active photoionization, J. Atmos. Sol.-Terr. Phy., 71, 477-485, 2009.

Rapp, M. and Thomas, G. E.: Modeling the microphysics of mesospheric ice particles: Assessment of current capabilities and basic sensitivities, J. Atmos. Sol.-Terr. Phy., 68, 715-744, 2006.

Renkwitz, T., Singer, W., Latteck, R., Stober, G., and Rapp, M.: Validation of the radiation pattern of the Middle Atmosphere Alomar Radar System (MAARSY), Adv. Radio Sci., 10, 1-9, doi:10.5194/ars-10-1-2012, 2012.

Renkwitz, T., Stober, G., Latteck, R., Singer, W., and Rapp, M.: New experiments to validate the radiation pattern of the Middle Atmosphere Alomar Radar System (MAARSY), Adv. Radio Sci., 11, 283-289, doi:10.5194/ars-11-283-2013, 2013.

Sato, T., Nakamura, T., and Nishimura, K.: Orbit Determination of Meteors Using the MU Radar, IEICE T. Commun., E83, 9 pp., 1990-1995, September, 2000.

Sparks, J., Janches, D., Nicolls, M. J., and Heinselman, C. J.: Seasonal and diurnal variability of the meteor flux at high latitudes observed using PFISR, J. Atmos. Solar-Terrest. Phys., 71, 644652, 2009.

Sparks, J. J., Janches, D., Nicolls, M. J., and Heinselman, C.: Determination of physical and radiant meteor properties using PFISR interferometry measurements of head echoes, J. Atmos. Sol.Terr. Phy., 72, 1221-1230, 2010.

Stober, G., Jacobi, C., and Singer, W.: Meteoroid mass determination from underdense trails, J. Atmos. Sol.-Terr. Phy., 73, 895900, 2011a.

Stober, G., Singer, W., and Jacobi, C.: Cosmic radio noise observations using a mid-latitude meteor radar, J. Atmos. Sol.-Terr. Phy., 73, 1069-1076, 2011b.

Stober, G., Jacobi, C., Matthias, V., Hoffmann, P., and Gerding, M.: Neutral air density variations during strong planetary wave activity in the mesopause region derived from meteor radar observations, J. Atmos. Sol.-Terr. Phy., 74, 55-63, 2012.

Stober, G., Schult, C., Baumann, C., Latteck, R., and Rapp, M.: The Geminid meteor shower during the ECOMA sounding rocket campaign: specular and head echo radar observations, Ann. Geophys., 31, 473-487, doi:10.5194/angeo-31-473-2013, 2013.

Valentic, T. A., Avery, J. P., Avery, S. K., and Livingston, R. C.: Self-Survey Calibration of Meteor Radar Antenna Arrays, IEEE T. Geosci. Remote, 35, 524-531, 1997.

Vondrak, T., Plane, J. M. C., Broadley, S., and Janches, D.: A chemical model of meteoric ablation, Atmos. Chem. Phys., 8, 70157031, doi:10.5194/acp-8-7015-2008, 2008.

Westman, A., Wannberg, G., and Pellinen-Wannberg, A.: Meteor head echo altitude distributions and the height cutoff effect studied with the EISCAT HPLA UHF and VHF radars, Ann. Geophys., 22, 1575-1584, doi:10.5194/angeo-22-1575-2004, 2004. 